\title{
Anatomical Variations of Celiac Trunk and Its Branching Pattern with Special Reference to Surgical Implications in Mysore Based Population
}

\author{
Vidya C.S. ${ }^{1}$, Shivanakarappa C. ${ }^{2}$, Sudha Kiran Das ${ }^{3}$, Santh Kumar ${ }^{4}$ \\ 1,2,3,4 Department of Anatomy, JSS Medical College, Mysore, Karnataka, India.
}

\section{ABSTRACT}

\section{BACKGROUND}

Celiac trunk (CT) is the first major abdominal branch of the aorta. Anatomic variations and accessory vessels have been reported with variable percentages. We report here a particularly rare variant involving absence of the celiac trunk in association with trifurcation of the common hepatic artery (CHA). The purpose of this study was to report the pattern of the celiac trunk and its anatomic variations in a sample of Mysore population.

\section{METHODS}

Celiac trunk dissection was performed in 10 fresh cadavers and 50 cases of contrast enhanced computed tomography (CECT) images of Mysore based subjects at JSS Medical College and Hospital aged 18 years and above were included. Celiac trunk variations, length, diameter, accessory vessels, and vertebral level of origin were described.

\section{RESULTS}

The branching pattern of coeliac trunk was observed in 60 cases (37 males, 23 females) by dissection and CECT scan method. Type I was found in 48 cases (80 \%), Type I form 2 a was found in 2 cases (3.3\%). Type II form 1 in 6 cases (10\%). Type III was observed in 1 case and in another case left hepatic artery (LHA) arising from coeliac trunk, Type VII was found in 2 cases (3.3\%). The length and diameter of coeliac trunk were analysed using descriptive statistics and mean \pm SD for length was $1.8 \pm 0.4$ and diameter $0.5 \pm 0.2$ respectively.

\section{CONCLUSIONS}

Awareness of CT variations is important in surgical resection, transplantation, and interventional radiology procedure.

\section{KEY WORDS}

Celiac Trunk, Variations, Morphometry, Contrast Enhanced Computed Tomography Scan Method
Corresponding Author: Dr. Vidya C. S.,

Department of Anatomy, JSS Medical College, Mysore, Karnataka, India.

E-mail: vidyacs@jssuni.edu.in

DOI: $10.14260 /$ jemds/2021/655

How to Cite This Article:

Vidya CS, Shivanakarappa C, Das SK, et al. Anatomical variations of celiac trunk and its branching pattern with special reference to surgical implications in Mysore based population. J Evolution Med Dent Sci 2021;10(37):3225-3230, DOI: 10.14260/jemds/2021/655

Submission 12-06-2021, Peer Review 23-08-2021, Acceptance 30-08-2021, Published 13-09-2021.

Copyright (c) 2021 Vidya C.S. et al. This is an open access article distributed under Creative Commons Attribution License [Attribution 4.0 International (CC BY 4.0)] 


\section{BACKGROUND}

Coeliac trunk is the anterior branch of abdominal aorta arising at the level of T12 to L1 vertebral bodies and mainly supplies the foregut. The coeliac trunk is very short, measuring 1.5 to $2 \mathrm{~cm}$ in length and 0.4 to $1.13 \mathrm{~cm}$ in diameter. The coeliac trunk branches into the left gastric, splenic, and common hepatic arteries. The left gastric artery (LGA) is the celiac trunk's smallest branch, curving directly around the lesser curvature, where it anastomoses with the right gastric artery. The splenic artery (SA) is the main branch of celiac trunk, running around the superior boundary of the pancreas and giving off narrow gastric arteries and the left gastro-epiploic artery.

The common hepatic artery splits into right gastric artery and gastroduodenal artery, with the distal part serving as the hepatic artery proper. From the common hepatic artery, the right and left hepatic arteries branches out, which ascends over the lesser omentum' s free edge. The gallbladder is supplied by the cystic artery, which branches out of the right hepatic artery. Bifurcation of the gastroduodenal artery through the right gastro-epiploic and superior pancreaticoduodenal arteries. ${ }^{1}$

The vitelline arteries are a pair of vessels that supply the yolk sac with nutrients during the embryonic stage and eventually merge to form arteries in the dorsal mesentery of the gut. The celiac, superior mesenteric, and inferior mesenteric arteries represent these in adults. ${ }^{2}$

Variations of origin and branching pattern may be due to developmental reason; the celiac trunk is subjected to morphology variability. Previous research has indicated that the celiac artery's origin, dimensions, and branching pattern are abnormal. ${ }^{3}$

The root as well as branching pattern of the celiac trunk are essential for proper vascular ligation and anastomosis during laparoscopic abdominal surgery and procedures such as liver transplantation. Until catheterization, vascular details are often essential for diagnostic contrast angiography in the presence of gastrointestinal bleeding. ${ }^{4}$ The correct diameter of the celiac trunk is critical in diagnostic imaging and to prevent problems during interventional radiological procedures since there is a wide range of variance in length and diameter. The rapid advancement in laparoscopic abdominal surgery has provided surgeons with a better appreciation and understanding of the abdominal organs' varying blood supply.

The anatomist is in charge of assessing arterial variety, which will help not only surgeons but also radiologists in creating precise imaging records. The advice Halsted left for surgeons was that the best way to avoid injury to blood vessels would be to identify them and also to correctly ligate them in the correct manner and site. ${ }^{5}$

Multidetector computed tomography, for example, aids not only in data collection but also in image post-processing on workstations. It is possible to gain knowledge that aids in the preparation of a particular surgical operation and helps to mitigate post-operative complications.

\section{Objective}

The current research was undertaken to learn more about the level of origin, variations in the celiac trunk's branches, and their dimensions in cadavers and images of multidetector CT scans, which will aid in the good outcome of hepatobiliary surgeries.

\begin{tabular}{|c|c|c|c|}
\hline Type & Branching Pattern & Form & $\begin{array}{c}\text { Trifurcation of the CT into LGA, } \\
\text { CHA and SA }\end{array}$ \\
\hline 1 & Trifurcation & $\begin{array}{c}2 \\
2 \mathrm{a} \\
2 \mathrm{~b} \\
2 \mathrm{c}\end{array}$ & $\begin{array}{c}\text { True tripod - common origin of LGA, CHA } \\
\text { and SA } \\
\text { False tripod - division into two branches } \\
\text { The LGA is the first branch } \\
\text { The CHA is the first branch } \\
\text { The SA is the first branch }\end{array}$ \\
\hline II & Bifurcation & $\begin{array}{l}1 \\
2 \\
3 \\
4 \\
5 \\
6 \\
7 \\
8 \\
9\end{array}$ & $\begin{array}{c}\text { Hepatosplenic trunk, LGA arising from } \\
\text { the AA } \\
\text { Hepatosplenic trunk, no normal LGA } \\
\text { Hepatosplenic trunk and gastro- } \\
\text { mesenteric trunk } \\
\text { Spleno-gastric trunk, CHA arising from } \\
\text { the AA } \\
\text { Spleno-gastric trunk, CHA arising from } \\
\text { the SMA } \\
\text { Spleno-gastric trunk, and hepato- } \\
\text { mesenteric trunk } \\
\text { Aepatogastric trunk, SA arising from the } \\
\text { AA } \\
\text { Hepatogastric trunk, SA arising from the } \\
\text { SMA } \\
\text { Hepatogastric trunk and } \\
\text { splenomesenteric trunk }\end{array}$ \\
\hline III & Additional branches & & \\
\hline IV & $\begin{array}{l}\text { Celiac - mesenteric trunk } \\
\text { (CT and SMA) }\end{array}$ & & \\
\hline $\mathrm{V}$ & $\begin{array}{l}\text { Variations in the origin of } \\
\text { the CHA }\end{array}$ & & \\
\hline VI & $\begin{array}{c}\text { Hepatosplenomesenteric } \\
\text { trunk, LGA arising } \\
\text { independently or as } \\
\text { branch }\end{array}$ & & \\
\hline VII & Absence of the CT & (LGA & A, CHA and SA arising independently) \\
\hline VIII & $\begin{array}{c}\text { Splenogastromesentric } \\
\text { trunk, }\end{array}$ & CHA & A arising independently or as a branch \\
\hline IX & $\begin{array}{l}\text { Splenogastric trunk } \\
\text { giving rise to a common } \\
\text { inferior phrenic trunk }\end{array}$ & & \\
\hline $\mathrm{X}$ & Celiac-bimeseneric trunk & & CT SMA and IMA \\
\hline \multicolumn{4}{|c|}{ Table 1. Panagouli's Classification Celiac Trunk ${ }^{6}$} \\
\hline
\end{tabular}

\section{METHODS}

This was a cross sectional study conducted in the Department of Anatomy, JSS Medical College and Hospital. A total of 60 subjects (37 males and 23 females) in age ranging from 20 70 years were included in which 10 cadavers by dissection method and 50 cases by contrast CT scan images from the department of Radiology, JSSMC \& Hospital, Mysuru were studied. This study was carried out from January 2020 to March 2021. Ethical clearance has been obtained from Institution Ethical Committee. Ref No JSS / MC / PG / 6929 / 2019 - 20 Dated 27 / 01 / 2020. Informed consent was obtained from the patients to study the CECT images. 60 subjects, 10 samples from dissection method and 50 samples from CT scan method were selected by convenient sampling technique due to Covid pandemic. 60 subjects (based on the reported incidence of variations of celiac trunk as \%), absolute allowable error.

\section{Dissection Method}

Peritoneum was opened by vertical incision after demonstration of muscles of anterior abdominal wall. Liver was pulled upwards to expose the lesser omentum. The anterior layer of peritoneum was removed from the lesser curvature of the stomach. It was further dissected as per dissection manual. The level of origin and branching pattern was noted. The origin and any variation of superior 
mesenteric artery was observed. The length was measured using Vernier callipers and diameter was measured using thread and measuring scale. The variations of celiac trunk and its branches were observed, painted and photographed.

CT scan method: A prospective review of contrast CT (CECT Philips company) abdominal scans was performed in those patients who were advised for contrast CT scan by Philips 128 slice CT/Multidetector CT. Definitions of level of origin of coeliac trunk were observed by skilled radiologists and variations of the same were documented. Axial source images remained the basis for observing vascular anatomy, however post processed 2D and 3D reformations contributed for accurate evaluation. The morphometric measurements of vessels (length, diameter) were analyzed in sagittal and coronal planes of multiplanar processed images. (MPR)

\section{Statistical Method}

Frequency of level of origin and variations of coeliac trunk was calculated and expressed as percentages. The descriptive statistics (Mean, SD) were obtained for length and diameter of coeliac trunk. The differences between means were interpreted; statistically significant at $\mathrm{P}<0.05$. Independent $\mathrm{t}$ test was performed to find out difference of length and diameter between the males and females, combined by dissection and CECT scan method. The statistical analysis was performed using Statistical Package for Social Sciences (SPSS version 22) (licensed to JSS AHER).

\section{RESULTS}

Observations of variations of branching pattern of coeliac trunk according to Panagouli's classification.

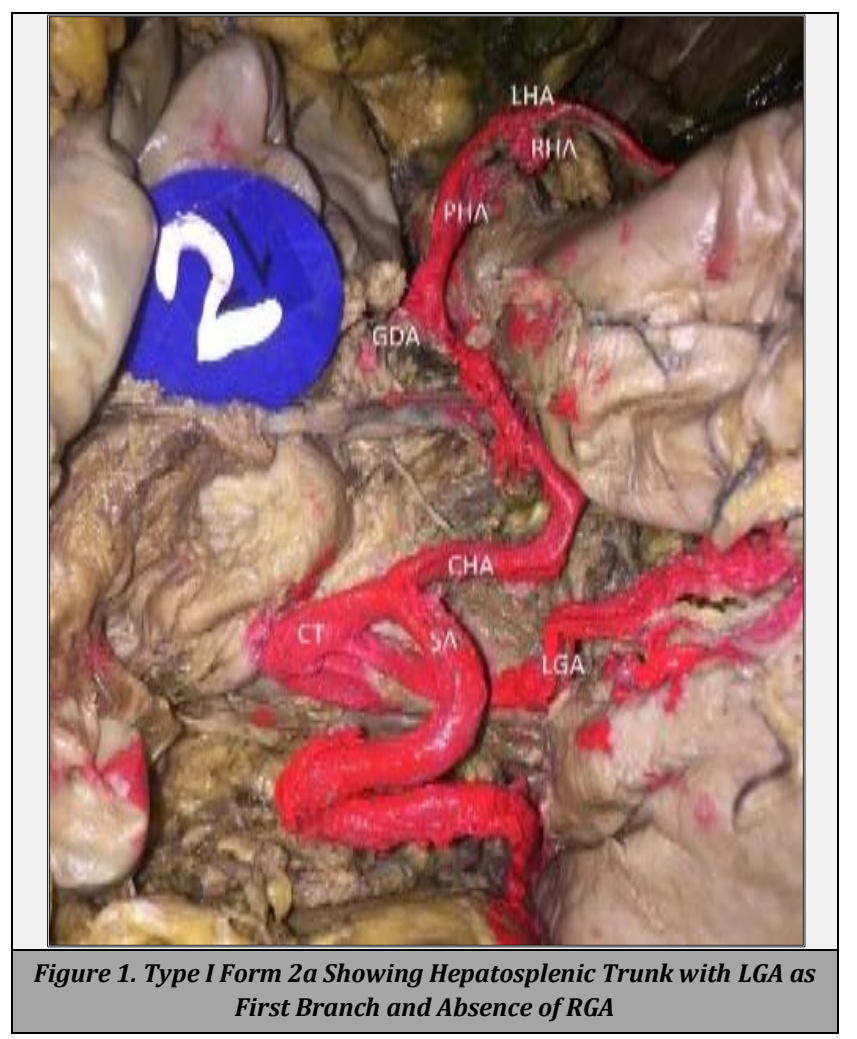

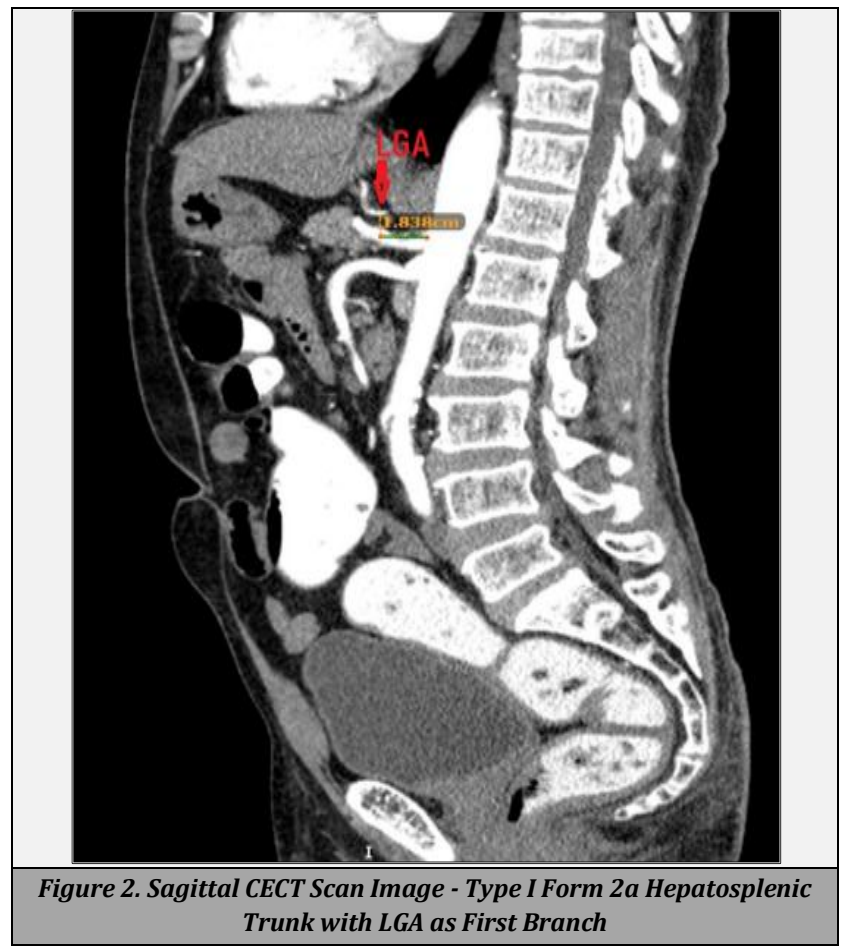

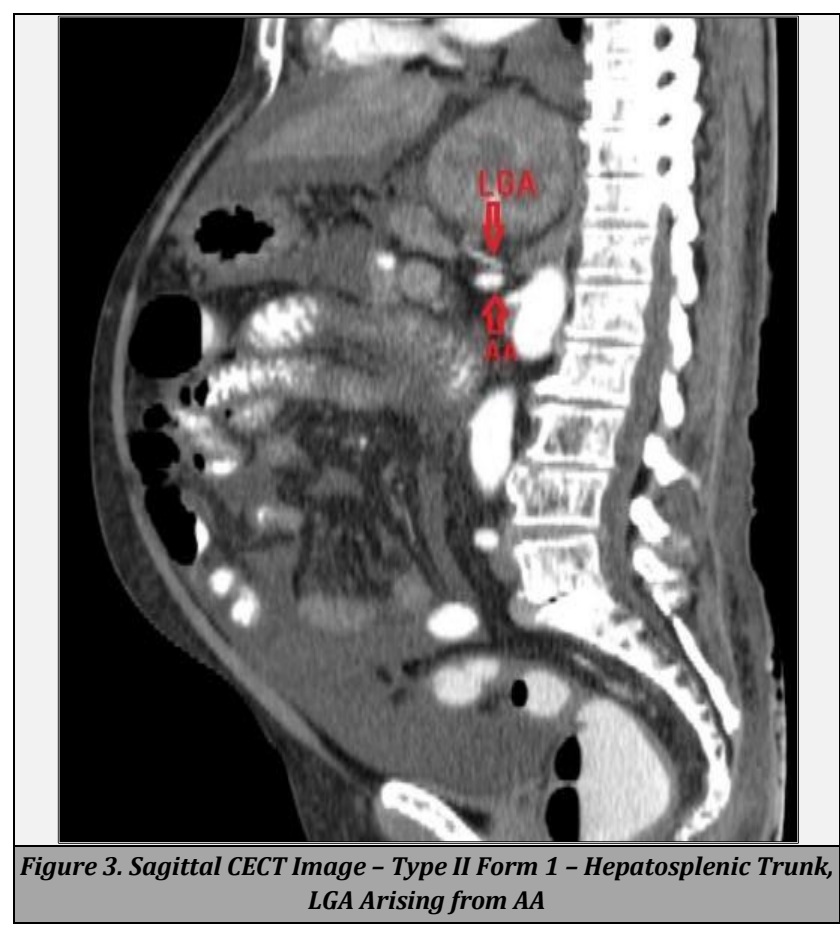

The level of origin of coeliac trunk from abdominal aorta was noted by dissection and CECT scan method. It was found that in 32 cases (53.3\%) origin of CT was at the level of T12 vertebra and in 26 cases (43.3\%), origin of CT was at the level of L1 vertebra. In 2 cases, coeliac trunk was absent and in 2 cases its shown in Table No.2.

The branching pattern of coeliac trunk was observed in 60 cases ( 37 males, 23 females) by dissection and CECT scan method. We found that according to Panagouli's classification Type I (Trifurcation of the CT into LGA, CHA and SA as shown in Figure 2) was found in 48 cases ( $80 \%$ ) out of which in 1 specimen LIPA was arising from splenic artery, in 1 specimen LSPA arising from splenic artery and in another specimen right gastric artery was arising from splenic artery. Type I Form 2a (hepatosplenic trunk, LGA arising as first branch of 
CT) was found in 2 cases (3.3\%). Type II form 1 (hepatosplenic trunk, LGA arising from the AA) in 6 cases (10 $\%)$.

Type III (Additional branch, LIPA arising from CT) was observed in 1 case and in another case LHA arising from coeliac trunk as shown in Figure 30. Type VII (absence of the CT with LGA, CHA and SA arising independently) was found in 2 cases $(3.3 \%)$. The length and diameter of coeliac trunk were analysed using descriptive statistics and mean \pm SD for length was $1.8 \pm 0.4$ and diameter $0.5 \pm 0.2$ respectively. The mean \pm SD for length was $1.8 \pm 0.3$ and $1.8 \pm 0.5$ in males and females. The mean \pm SD for diameter was $0.5 \pm 0.2$ for both males and females. There was no significant difference observed in length and diameter of coeliac trunk in males and females $\mathrm{P}>0.05$.

\begin{tabular}{|c|c|c|c|c|}
\hline Types & $\begin{array}{l}\text { No. of Specimens } \\
\text { (Males = 37) }\end{array}$ & $\%$ & $\begin{array}{l}\text { No. of Specimens } \\
\text { (Females }=23 \text { ) }\end{array}$ & $\%$ \\
\hline Type I & 31 & $51 \%$ & 17 & $28.3 \%$ \\
\hline Type I form 2a & 1 & $1.7 \%$ & 1 & $1.7 \%$ \\
\hline Type II form 1 & 3 & $5 \%$ & 3 & $5 \%$ \\
\hline Type III & 1 & $1.7 \%$ & 1 & $1.7 \%$ \\
\hline Type VII & 1 & $1.7 \%$ & 1 & $1.7 \%$ \\
\hline \multicolumn{5}{|c|}{$\begin{array}{c}\text { Table 2. Frequency of Variations of Branching Pattern of Coeliac Trunh } \\
\text { by Dissection and CECT Scan Method in Males and Females According } \\
\text { to Panagouli's Classification }\end{array}$} \\
\hline
\end{tabular}

\begin{tabular}{|ccc|}
\hline Parameters & Mean \pm SD & P Value \\
Length (in cm) males & $1.8 \pm 0.3$ & 1.0 \\
Length (in cm) females & $1.8 \pm 0.5$ & 1.0 \\
Diameter (in cm) males & $0.5 \pm 0.2$ & 1.0 \\
Diameter (in cm) females & $0.5 \pm 0.2$ & 1.0 \\
\hline Table 3. Mean \pm SD for Length and Diameter of Coeliac Trunk in Males \\
and Females Combinedly by Dissection Method and CECT Scan Method \\
\hline
\end{tabular}

\section{DISCUSSION}

The study was done in the Anatomy and Radiology departments, JSS Medical College and Hospital Mysore, on randomly selected 10 specimens and 50 cases of CECT images. The data was analysed to study the level of origin length, diameter, and branching pattern of the celiac trunk. The coeliac trunk, the abdominal aorta's first ventral branch, supplies the supraceliac abdominal compartment with blood. To supply the foregut, it usually branches into the splenic, typical hepatic, and left gastric arteries. ${ }^{7}$ Understanding its variations is critical for correct illness interpretation, diagnostic imaging, and deciding on the best elective approach in surgical or interventional radiological therapy. ${ }^{3}$

Our research revealed that the celiac trunk has roots at several stages, between the $\mathrm{T}-11$ and the $\mathrm{L}-1$ vertebra. Previously, related variations in origin were established, with the majority of celiac trunk origins arising at the T12 spinal stage in $40 \%$ of cases. With a T12 level of $12 \%$, the celiac trunk started opposite the T11. The levels of T12 and L1 vertebrae are $32 \%$ opposite each other. The ratio is at the L1 vertebral level. Celiac axis compression syndrome (CACS) is characterized by severe epigastric pain, nausea, and vomiting after a postprandial. A high celiac trunk origin is the cause. We found no cases of celiac axis compression due to a high celiac trunk origin. ${ }^{8}$

In the current investigation, the celiac trunk trifurcation (Type I) was seen in $80 \%(48 / 60)$ of the patients, which is nearly similar to what has previously been identified. Celiac trunk trifurcation was observed in $85.1 \%$ of cadaveric investigations, $89.6 \%$ of imaging investigations, and 95.4 percent of liver transplantation investigations, respectively. In comparison, cadaveric studies revealed a prevalence of celiac trunk trifurcation of $40 \%$ by Chitra, ${ }^{9} 60 \%$ by Nelson et al. ${ }^{10} 61.8$ percent by Mburu et al. ${ }^{11}$, and 63.6 percent by Farghadani. ${ }^{12}$ Lezzi et al. ${ }^{13}$ reported a classical structure of the celiac trunk morphology in 72.1 percent of cases using multidetector row CT angiography, and Winston et al. ${ }^{14}$ recorded trifurcation in $51 \%$ of cases, which is less than our study's proportion. The celiac trunk's false tripod was found in 3.3 percent $(2 / 60)$ of the participants in the study. The most prevalent type of false tripod, was the left gastric artery functioning as the first branch of the celiac trunk because of a hepatosplenic trunk. David F discovered $36.4 \%$ of a false tripod. ${ }^{8}$ With a frequency of $7 \%$, the most common variant of the celiac trunk is bifurcation (Type II form I). ${ }^{15}$ In the current study, the prevalence of celiac trunk bifurcation has been $10 \%(6 / 60)$. In $76(61.7 \%)$ of the cases, the celiac trunk was trifurcated, whereas $22(17.9 \%)$ were bifurcated and 25 had collateral branches $(20.3 \%)^{11}$, hepatosplenic trunk seen in $5.9 \%$ of the cases. ${ }^{13}$ Other authors also reported that $15 \%$ of the cases in their study shows hepatosplenic trunk ${ }^{16,17}$ It is also consistent mostly with findings of the current study. (5\%).

Vandamme et al. ${ }^{18}$ refer to additional branches (Type III) as tributaries. In $50 \%$ of instances, the celiac trunk grows one to two collateral arteries. Inferior phrenic arteries, single or double, which have been found in $40 \%$ of cases, are the most common extra branches. ${ }^{19}$ Greig et al. ${ }^{20}$ found that the celiac trunk accounted for 46.8 percent of dissections, in relation to cases originating from the abdominal aorta, which accounted for $45.1 \%$ of cases. The phrenic arteries formed independently of the celiac trunk in 20.9 percent of cadavers, however, 12.2 percent of specimens have a similar phrenic trunk. Basile et al. published a multidetector computed tomography study. ${ }^{21}$ In our study, additional vessels were found in $3.3 \%(2 / 60)$ by dissection and CT scan.

The absence of a celiac trunk is among the rarest celiac trunk anomalies, as stated by several authors. ${ }^{22}$ The three primary arteries originate directly from the abdominal aorta or superior mesenteric artery in three of our patients $(0.6$ \%). ${ }^{16}$ In their preparation, they discovered two cases. In one example, the three arteries split from the aorta, whereas in the other, the superior mesenteric artery was split from the common hepatic artery. ${ }^{18,23}$ According to Matusz et al. ${ }^{24}$ only $0.19 \%$ of patients had no celiac trunk, $6.09 \%$ had an incomplete celiac trunk and $90.7 \%$ had a complete celiac trunk. In our study, we discovered that $3.3 \%(2 / 60)$ of the patients did not have CT. Our findings agree with the findings of Moncada et al. ${ }^{25}$ who discovered a range of $0.9 \mathrm{~cm}$ to 3.6 $\mathrm{cm}$, Latarjet and Ruiz-Liard, ${ }^{26}$ who recorded a range of $0.9 \mathrm{~cm}$ to $3.6 \mathrm{~cm}$, and Wadhwa and Soni, who discovered a range of $0.9 \mathrm{~cm}$ to $3.6 \mathrm{~cm}$. The celiac trunk's diameter was found to vary from $0.2 \mathrm{~cm}$ to $0.9 \mathrm{~cm}$ which is in near agreement with that by Singh et al. ${ }^{27}$ who reported a range between $0.4 \mathrm{~cm}$ and $1.0 \mathrm{~cm}$.

\section{Surgical Implications of Coeliac Trunk}

Knowledge of the anatomical variations of celiac trunk is of extreme clinical importance during surgery and interventional radiology procedures. Recognition in detail of 
arterial dimension and branch anomaly of celiac trunk are mandatory before liver surgery including liver transplantation, tumour resection or chemoembolisation of liver malignancy and abdominal laparoscopic surgeries to prevent complications. ${ }^{28}$

Knowing which variation group a patient belongs to will aid a surgeon during multiple pancreatic operations that include knowledge of the gastric arteries in splenectomies. Since middle colic artery is a branch of superior mesenteric artery, these variations must be taken into account during colectomy and other colon surgical procedures. There is a chance of harm to the variation of the middle colic artery or anastomosis between coeliac trunk and superior mesenteric branches in surgeries that involve incision of the supposed avascular area of the transverse mesocolon (as in retrocolic anastomoses).

In liver transplantation surgeries, technical improvement must be made both during organ procurement and reanastomosis in the recipient, the ability to recognise the multiple hepatic arteries is critical. The accessory hepatic arteries provide an external supply of arterial blood to the liver while proper hepatic artery is present. Coeliac trunk variations should be assessed during surgery as well as during non-surgical patient evaluation. In order to make proper corrections when anastomosing the right arteries at post-operative closing, variations in trunk anatomy must be thoroughly researched. In addition, arterial differences are critical when matching organ recruitment for transplantation. The accessory hepatic arteries are an additional source of vasculature supplying the liver with arterial blood when proper hepatic artery is present. The variations in the anatomy of coeliac trunk must be carefully understood in order to make proper adjustments in anastomosing the proper arteries in post-operative procedure.

\section{CONCLUSIONS}

Anatomy of coeliac trunk and its variation play critical role in evaluation before surgical interventions, transplantation, and interventional procedure of abdomen. Dissection and CECT scan methods were used to determine the celiac trunk's level of origin from abdominal aorta. The origin of CT was found in 32 cases (53.3\%) at the T12 vertebral level, and in 26 cases (43.3\%) at the L1 vertebral level. Coeliac trunk was absent in two cases. Normal branching pattern were identified in 48/60 case, bifurcation type II form 1 (hepatosplenic trunk, LGA arises from the AA) in 6 cases (10\%). Type III (Additional branch, LIPA arising from CT) was observed in 1 case and in another case LHA arising from coeliac trunk which was rare variant. Type VII (Absence of the CT with the rise of LGA, CHA, and SA independently) was found in 2 cases (3.3\%). The length and diameter of coeliac trunk were analysed using descriptive statistics and mean \pm SD for length was $1.8 \pm 0.4$ and diameter $0.5 \pm 0.2$ respectively.

In conclusion, awareness of coeliac trunk variations is important in surgical resection and transplantation. In case of complex interventional procedure, this variation should be described precisely in the radiological report because of their considerable impact on subsequent surgical and interventional radiology procedure. So, prior knowledge of
CT variation can reduce the incidence of post-operative complications.

\section{Limitations of This Study}

1. Sample size by dissection method was reduced because of Covid-19 pandemic.

2. Accuracy of luminal diameter depends on arterial course and necessitating need for reconstruction using advance software

3. Inaccurate timing can impede filling of the arteries resulting in poor opacification.

Data sharing statement provided by the authors is available with the full text of this article at jemds.com.

Financial or other competing interests: None.

Disclosure forms provided by the authors are available with the full text of this article at jemds.com.

\section{REFERENCES}

[1] Standring S. Gray's Anatomy. The Anatomical Basis of Clinical Practice. 40th edn. Elsevier Health Sciences 2008: p. 11073-4.

[2] Sadler TW. Langman's Medical Embryology Textbook. 13 $3^{\text {th }}$ edn. Philadelphia: Wolters \& Kulwer 2015: p. 205.

[3] Sehgal G, Srivastava AK, Sharma PK, et al. Morphometry of the celiac trunk: a multidetector computed tomographic angiographic study. Journal of the Anatomical Society of India 2013;62(1):23-7.

[4] Ragupathi S, Patil KS. Anatomical variations of celiac axis artery in Karaikal population: MDCT Angiographic findings. International Journal of Anatomy Radiology and Surgery 2019;8(1):001-3.

[5] Pushplalatha K, Bhatt D, ShamSundar NM. A study of anatomical variations in the origin, length and branches of celiac trunk and its surgical significance. International Journal of Anatomy and Research 2016;4(1):1781-8.

[6] Pinal-Garcia DF, Nuno-Guzman CM, Gonzalez-Gonzalez ME, et al. The celiac trunk and its anatomical variations: cadaveric study. Clin Med Res 2018;10(4):321-9.

[7] Babu DE, Khrab P. Coeliac trunk variation, review with proposed new classification. International Journal of Anatomy and Research 2013;1(3):165-70.

[8] Reuter SR. Accentuation of celiac compression by the median arcuate ligament of the diaphragm during deep expiration. Radiology 1971;98(3):561-4.

[9] Chitra R. Clinically relevant variations of the coeliac trunk. Singapore Med J 2010;51(3):216-9.

[10] Nelson TM, Pollak R, Jonasson O, et al. Anatomic variants of the celiac, superior mesenteric and inferior mesenteric arteries and their clinical relevance. Clin Anat 1988;1(2):75-91.

[11] Mburu KS, Alexander OJ, Hassan S, et al. Variations in the branching pattern of the celiac trunk in a kenyan population. Int J Morphol 2010;28(1):199-204.

[12] Farghadani M, Momeni M, Hekmatnia A, et al. Anatomical variation of celiac axis, superior mesenteric artery and hepatic artery: evaluation with multidetector computed tomography angiography. J Res Med Sci 2016;21:129. 
[13] Iezzi R, Cotroneo AR, Giancristofaro $D$, et al. Multidetector-row CT angiographic imaging of the celiac trunk: anatomy and normal variants. Surg Radiol Anat 2008;30(4):303-10.

[14] Winston CB, Lee NA, Jarnagin WR, et al. CT angiography for delineation of celiac and superior mesenteric artery variants in patients undergoing hepatobiliary and pancreatic surgery. AJR Am J Roentgenol 2007;189(1):13-9.

[15] Panagouli E, Venieratos D, Lolis E, et al. Variations in the anatomy of the celiac trunk: a systematic review and clinical implications. Ann Anat 2013;195(6):501-11.

[16] Lipshutz B. A composite study of the coeliac axis artery. Ann Surg 1917;65(2):159-69.

[17] Chen H, Yano R, Emura S, et al. Anatomic variation of the celiac trunk with special reference to hepatic artery patterns. Ann Anat 2009;191(4):399-407.

[18] Vandamme JP, Bonte J. The branches of the celiac trunk. Acta Anat (Basel) 1985;122(2):110-14.

[19] Loukas M, Hullett J, Wagner T. Clinical anatomy of the inferior phrenic artery. Clin Anat 2005;18(5):357-65.

[20] Greig HW, Anson BJ, Coleman SS. The inferior phrenic artery; types of origin in 850 body-halves and diaphragmatic relationship. Q Bull Northwest Univ Med Sch 1951;25(4):345-50.

[21] Basile A, Tsetis D, Montineri A, et al. MDCT anatomic assessment of right inferior phrenic artery origin related to potential supply to hepatocellular carcinoma and its embolization. Cardiovasc Intervent Radiol 2008;31(2):349-58.

[22] Song SY, Chung JW, Yin YH, et al. Celiac axis and common hepatic artery variations in 5002 patients: systematic analysis with spiral CT and DSA. Radiology 2010;255(1):278-88

[23] Saga T, Hirao T, Kitashima S, et al. An anomalous case of the left gastric artery, the splenic artery and hepatomesenteric trunk independently arising from the abdominal aorta. Kurume Med J 2005;52 (1-2):49-52.

[24] Matusz P, Miclaus GD, Ples H, et al. Absence of the celiac trunk: case report using MDCT angiography. Surg Radiol Anat 2012;34(10):959-63.

[25] Moncada R, Reynes C, Churchill R, et al. Normal vascular anatomy of the abdomen on computed tomography. Radiol Clin North Am 1979;17(1):25-37.

[26] Latarjet M, Ruiz-Liard A. Anatomia Humana. Vol. 2. 2 ${ }^{\text {nd }}$ edn. Sao Paulo: Medicina Panamericana Editora do Brasil Ltd., 1989.

[27] Singh BGP, Bhatt CR, Patel SV, et al. Morphometric study of coeliac trunk specific reference to hepatic artery pattern in the West-Indian population. Indian J Surg 2014;76(5):359-62.

[28] Marjeta T, Erjona A. Anatomical variations of celiac trunk anatomy and their clinical importance. International Journal of Science and Research 2015;4(12):12-14. 